\title{
Abnormal face identity coding in the middle fusiform gyrus of two brain-damaged prosopagnosic patients
}

Citation for published version (APA):

Steeves, J., Dricot, L., Goltz, H. C., Sorger, B., Peters, J. C., Milner, A. D., Goodale, M. A., Goebel, R., \& Rossion, B. (2009). Abnormal face identity coding in the middle fusiform gyrus of two brain-damaged prosopagnosic patients. Neuropsychologia, 47(12), 2584-2592.

https://doi.org/10.1016/j.neuropsychologia.2009.05.005

Document status and date:

Published: 01/01/2009

DOI:

10.1016/j.neuropsychologia.2009.05.005

Document Version:

Publisher's PDF, also known as Version of record

Document license:

Taverne

Please check the document version of this publication:

- A submitted manuscript is the version of the article upon submission and before peer-review. There can be important differences between the submitted version and the official published version of record.

People interested in the research are advised to contact the author for the final version of the publication, or visit the DOI to the publisher's website.

- The final author version and the galley proof are versions of the publication after peer review.

- The final published version features the final layout of the paper including the volume, issue and page numbers.

Link to publication

\footnotetext{
General rights rights.

- You may freely distribute the URL identifying the publication in the public portal. please follow below link for the End User Agreement:

www.umlib.nl/taverne-license

Take down policy

If you believe that this document breaches copyright please contact us at:

repository@maastrichtuniversity.nl

providing details and we will investigate your claim.
}

Copyright and moral rights for the publications made accessible in the public portal are retained by the authors and/or other copyright owners and it is a condition of accessing publications that users recognise and abide by the legal requirements associated with these

- Users may download and print one copy of any publication from the public portal for the purpose of private study or research.

- You may not further distribute the material or use it for any profit-making activity or commercial gain

If the publication is distributed under the terms of Article $25 \mathrm{fa}$ of the Dutch Copyright Act, indicated by the "Taverne" license above, 


\title{
Abnormal face identity coding in the middle fusiform gyrus of two brain-damaged prosopagnosic patients
}

\author{
Jennifer Steeves ${ }^{\mathrm{a}, *}$, Laurence Dricot $^{\mathrm{b}}$, Herbert C. Goltz ${ }^{\mathrm{c}}$, Bettina Sorger ${ }^{\mathrm{d}}$, Judith Peters ${ }^{\mathrm{d}}$, \\ A. David Milner ${ }^{\mathrm{e}}$, Melvyn A. Goodale ${ }^{\mathrm{f}}$, Rainer Goebel ${ }^{\mathrm{d}}$, Bruno Rossion ${ }^{\mathrm{b}, * *}$ \\ a Centre for Vision Research, Department of Psychology, York University, Toronto, Canada \\ ${ }^{\mathrm{b}}$ Center for Neuroscience, University of Louvain, Belgium

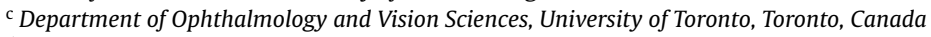 \\ d Faculty of Psychology and Neuroscience, Maastricht University, Maastricht, The Netherlands \\ e Cognitive Neuroscience Research Unit, Durham University, Durham, UK \\ ${ }^{\mathrm{f}}$ CIHR Group for Action and Perception, The University of Western Ontario, London, Canada
}

\section{A R T I C L E I N F O}

\section{Article history:}

Received 6 November 2008

Received in revised form 4 May 2009

Accepted 10 May 2009

Available online 18 May 2009

\section{Keywords:}

Face perception

Face recognition

Prosopagnosia

Fusiform gyrus

Inferior occipital cortex

fMRI

FFA

OFA

LOC

\begin{abstract}
A B S T R A C T
We report a functional magnetic resonance imaging (fMRI) adaptation study of two well-described patients, DF and PS, who present face identity recognition impairments (prosopagnosia) following braindamage. Comparing faces to non-face objects elicited activation in all visual areas of the cortical face processing network that were spared subsequent to brain damage. The common brain lesion in the two patients was in the right inferior occipital cortex, in the territory of the right "occipital face area" ('OFA'), which strengthens the critical role of this region in processing faces. Despite the lesion to the right 'OFA', there was normal range of sensitivity to faces in the right "fusiform face area" ('FFA') in both patients, supporting a non-hierarchical model of face processing at the cortical level. At the same time, however, sensitivity to individual face representations, as indicated by release from adaptation to identity, was abnormal in the right 'FFA' of both patients. This suggests that the right 'OFA' is necessary to individualize faces, perhaps through reentrant interactions with other cortical face sensitive areas. The lateral occipital area (LO) is damaged bilaterally in patient DF, who also shows visual object agnosia. However, in patient PS, in whom LO was spared, sensitivity to individual representations of non-face objects was still found in this region, as in the normal brain, consistent with her preserved object recognition abilities. Taken together, these observations, which fruitfully combine functional imaging and neuropsychology, place strong constraints on the possible functional organization of the cortical areas mediating face processing in the human brain.
\end{abstract}

(c) 2009 Elsevier Ltd. All rights reserved.

\section{Introduction}

Despite its apparent simplicity, deriving a full percept of an individual face is one of the most complex tasks performed by the human visual system. Lesion studies (e.g., Damasio, Damasio, \& Van Hoesen, 1982; Sergent \& Signoret, 1992), intracranial recordings (Allison et al., 1994) and functional neuroimaging investigations (e.g., Haxby, Hoffman, \& Gobbini, 2000; Sergent, Ohta, \&

\footnotetext{
* Corresponding author at: Centre for Vision Research, Department of Psychology, York University, 4700 Keele St., Toronto, ON M3J 1P3, Canada.

Tel.: +1 416736 2100x20452; fax: +1 4167365814 .

** Corresponding author at: Unité Cognition \& Développement, Université Catholique de Louvain, 10 Place du Cardinal Mercier, 1348 Louvain-la-Neuve, Belgium. Tel.: +32 10 478788; fax: +32 10472774 .

E-mail addresses: steeves@yorku.ca (J. Steeves), bruno.rossion@uclouvain.be (B. Rossion).
}

MacDonald, 1992) of the human brain have shown that this function relies primarily on a network of areas located in the occipitotemporal cortex. Functional magnetic resonance imaging (fMRI) studies in particular have shown that a subset of these areas present a strong preferential response to faces, including the so-called "fusiform face area" ('FFA', e.g., Kanwisher, McDermott, \& Chun, 1997) in the middle fusiform gyrus, the "occipital face area" in the inferior occipital cortex ('OFA', e.g., Gauthier et al., 2000), as well as an area located in the posterior part of the superior temporal sulcus (pSTS; e.g., Puce, Allison, Gore, \& McCarthy, 1995). These three bilateral areas, which show a strong right hemisphere advantage, are thought to form the core system for normal face perception (Haxby et al., 2000; Ishai, 2008).

In an attempt to further clarify the functional neuroanatomy of face perception, a few fMRI studies (Marotta et al., 2001; Rossion et al., 2003; Steeves et al., 2006) have measured neural responses to pictures of faces in neurological patients suffering 
from prosopagnosia-the inability to individualize faces following brain damage (Bodamer, 1947; Quaglino \& Borelli, 1867). A detailed investigation of patient PS, a rare case of prosopagnosia without visual object agnosia, showed right hemisphere 'FFA' activation despite a structurally damaged right inferior occipital cortex and no evidence of right 'OFA' activation (Rossion et al., 2003; Sorger, Goebel, Schiltz, \& Rossion, 2007). In a similar vein, this observation of right 'FFA' activation without ipsilateral 'OFA' was also recently reported in patient DF (Steeves et al., 2006), who suffers from visual form agnosia (an inability to recognize objects based on shape) in addition to prosopagnosia (Milner et al., 1991). This latter patient has extensive bilateral damage to lateral occipital cortex and shows no evidence of 'OFA' activation in either hemisphere. Taken together, these observations place strong constraints on the neurofunctional organization of face perception in the normal brain (Rossion, 2008). First, they indicate that the right 'OFA' - the common region within the face-preferential cortical network that is damaged in both patients - must be a critical component of the face perception network. This observation is corroborated by a recent retrospective analysis of the overlap of human patient lesions from structural MRI (Bouvier \& Engel, 2006). Second, these observations suggest that, in contrast to a hierarchical feedforward model for face perception (Haxby et al., 2000; Ishai, 2008), the 'FFA' can be activated without ipsilateral 'OFA' inputs, perhaps through direct functional connections originating from striate and extrastriate cortical areas (Rossion, 2008).

More recent neuroimaging studies of patient PS have shown that the fMRI signal in the right 'FFA', despite showing a normal range of preferential activation to faces, does not show any evidence of sensitivity to discrimination of individual faces (Dricot, Sorger, Schiltz, Goebel, \& Rossion, 2008; Schiltz et al., 2006). Specifically, the fMRI response in this area fails to show a larger response for faces of different identities (presented in a block or as pairs of face stimuli) compared to the presentation of faces of the same identity. This stands in contrast to the strong effect of a release from adaptation with fMRI for different face identities that is found in this area in the normal healthy brain (e.g., Gauthier et al., 2000; Grill-Spector \& Malach, 2001; Schiltz et al., 2006; Winston, Henson, Fine-Goulden, \& Dolan, 2004) or even in patients with congenital prosopagnosia (Avidan, Hasson, Malach, \& Berhmann, 2005). This observation supports the hypothesis that a critical role of the right 'OFA' in face perception is not simply to detect and categorize a stimulus as a face - a function that is preserved for both PS and DF - but more importantly to assist in deriving an individual fine-grained face representation, perhaps through reentrant interactions between the 'FFA' and the 'OFA' (Rossion, 2008; Rossion et al., 2003; Schiltz et al., 2006).

As a result, this proposal would necessarily predict that face identity coding - as tested through fMRI adaptation - should also be impaired in the 'FFA' of patient DF. This critical test was the main goal of the present collaborative study, in which we sought to test and contrast both patients in an identical face identity adaptation paradigm. Our objectives were threefold. First, we aimed to replicate the observation of face-preferential activation in the fusiform gyrus ('FFA') in patient DF that had been previously demonstrated using a block design (Steeves et al., 2006) but in the present experiment using an event-related fMRI paradigm. This paradigm is more conservative, in that it is less sensitive to potential confounds of subject's expectations and attentional biases when compared to the block design face localizer used previously. Second, we sought to test the hypothesis that patient DF's 'FFA' in both hemispheres would show a larger response to faces compared to objects, yet would be insensitive to differences in face identity unlike normal controls. Finally, while patient PS has normal object perception ('pure prosopagnosia'), DF is profoundly impaired in both face and object perception, in particular when she has to discriminate indi- vidual exemplars of the same object class (Humphrey, Goodale, Jakobson, \& Servos, 1994). Hence, given that the 'FFA' also shows a robust response to non-face objects (e.g., Grill-Spector et al., 2006), we sought to test and compare release from adaptation in fMRI to both object and face identity in the two patients. Our predictions were: (1) an absence of adaptation effects for face identity in the both patients in the FFA and (2) significant adaptation effects for object identity in patient PS in the right 'FFA', but not for patient DF in either FFA.

Finally, it is important to note that we compare and contrast neuroimaging data from two brain-damaged patients in the same neuroimaging experiment - patients who have been studied extensively and characterized previously as single case studies by independent research groups - and the present work provides a unique opportunity to strengthen our understanding of the functional neuroanatomy of face and object perception in both the healthy and neurologically damaged human brain.

\section{Materials and methods}

\subsection{Subjects}

Patient DF is a female, 51 years of age at the time of testing, whose neuropsychological profile has been described in detail previously (e.g., Humphrey et al., 1994; James, Culham, Humphrey, Milner, \& Goodale, 2003; Milner et al., 1991; Servos, Goodale, \& Humphrey, 1993). Her primary neurological symptoms are profound visual form agnosia and prosopagnosia. She shows relatively normal static perimetry in the central visual field up to $30^{\circ}$ eccentricity but with some upper right quadrant loss (see Milner et al., 1991). Neuroimaging studies of patient DF's brain have been reported in James et al. (2003) and Steeves et al. (2004, 2006). An extensive description of DF's behavioural and neural response to face images is found in Steeves et al. (2006). In brief, however, she is unable to recognize face identity, gender or emotional expression but she can generally categorize faces and discriminate faces from objects that she cannot recognize. Patient DF also shows robust activation for face images within the "FFA", which is normal in terms of amplitude and spatial extent, bilaterally, with a block design face/scene localizer but she does not show face sensitive responses in the inferior occipital cortex (i.e., no "OFA").

Patient PS is a female, 56 years of age at the time of testing, whose neuropsychological profile and brain damage has been described in detail previously (Caldara et al., 2005; Rossion et al., 2003; Schiltz et al., 2006; Sorger et al., 2007). Her presenting neurological symptom is prosopagnosia and unlike patient DF, she does not present object recognition difficulties. Patient PS has normal visual fields, with the exception of a small left paracentral scotoma. The data collected on PS have been recently reported as a subset of a larger study (Dricot et al., 2008) that tested identity adaptation to faces with an independent localizer. This independent localizer was unavailable for patient DF due to limited scanning time and as a result the present data include a re-analysis of the Dricot et al. (2008) data so that the analysis for patient DF and PS is exactly the same.

In addition to the two patients, four neurologically intact participants (age: 25-35 years, two female) as well as one age-matched control participant (S5, 56 years of age, female) were tested. While it has been shown that the profile of activation in the right middle fusiform gyrus remains stable across decades (Brodtmann, Puce, Syngeniotis, Darby, \& Donnan, 2003) and therefore perhaps not necessary to ensure exact age-matching of participants, we also include the data from the age-matched control.

The patients and the control subjects gave informed written consent prior to the fMRI experiments. The study conformed to the Declaration of Helsinki and was approved by the Ethics Committees of the Department of Medicine at the University of Louvain and the York University Office of Research Ethics. Control subjects and PS were strongly right-handed according to the Edinburgh Inventory (Oldfield, 1971) and patient $\mathrm{DF}$ is also right handed.

\subsection{Stimuli and procedures}

Participants viewed three runs of 80 pairs of stimuli during fMRI recordings. The stimuli were pictures of faces and butterflies as shown in Fig. 1. Thirty-two face and 32 butterfly images were used in an event-related design. There were four conditions of interest: two different face identities, two identical face identities, two different butterflies, and two identical butterflies in each pair. Finally, a fifth condition of a butterfly followed by a face image (or the opposite order for half of the trials) was used and participants were asked to respond to these face-object pair trials by pressing a response key. This task was well suited to the goals of the experiment because it ensured that the participants were attending to the stimuli, and it was a task that both patients could perform well. [DF has been shown previously to be able to categorize faces even though she cannot rec- 


\begin{tabular}{cccc} 
Stimulus 1 & $\begin{array}{l}\text { White } \\
\text { Screen }\end{array}$ & $\begin{array}{c}\text { Stimulus 2 } \\
\text { (spatially jittered) }\end{array}$ & $+\quad$ IS| \\
\hline 1000 & 500 & $\begin{array}{c}1000 \\
\text { Time }(\mathrm{ms})\end{array}$ & 5000, 6250 or 7500
\end{tabular}
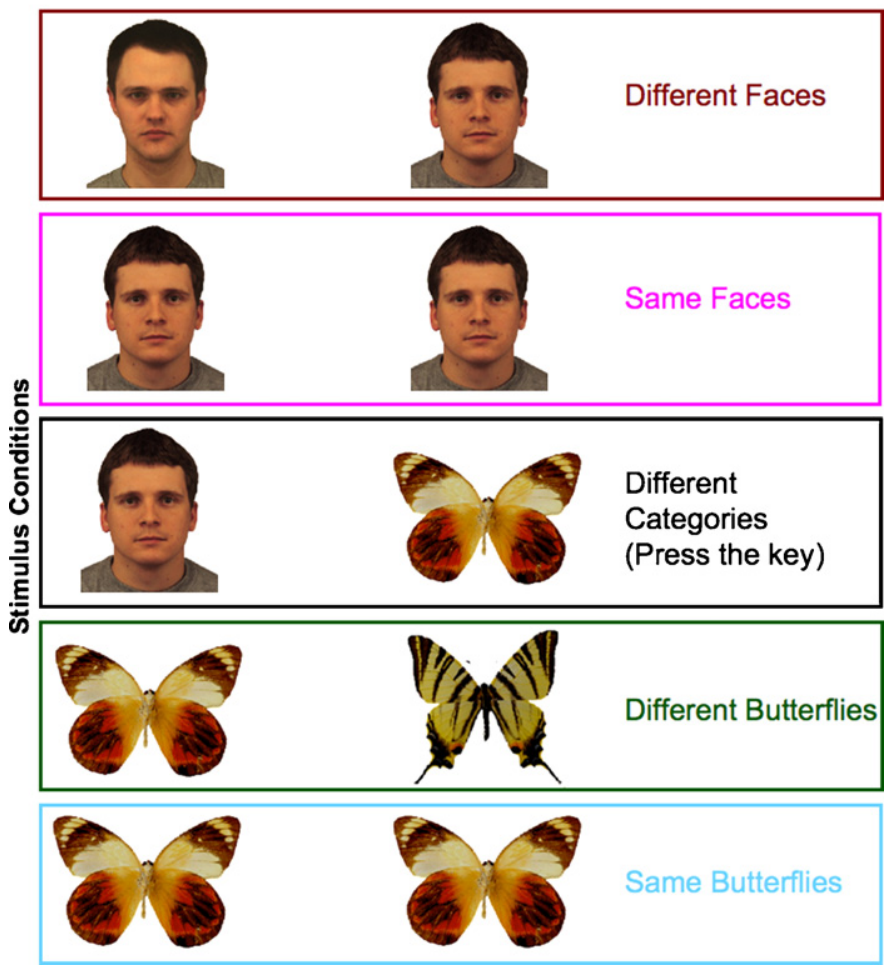

Fig. 1. Stimuli and task used in the experiment, with the time line of the presentation of events shown across the top.

ognize them (Steeves et al., 2006).] Further, this task ensured that the factors of interest of the study (category effect: faces versus butterflies; adaptation effect: same versus different identities) would not be contaminated by any decisional and/or motor processes since the behavioural task was completely orthogonal to the test factors in the study, and any difference between patients and the controls could not be attributed to general processing difficulties on the trials of interest.

There were 16 trials per condition per run and the order of conditions was fully randomized within a run. Within a trial, the first stimulus of a pair was presented for $1000 \mathrm{~ms}$ followed by a blank screen for $500 \mathrm{~ms}$ and thereafter by the second stimulus of the pair, which was also presented for $1000 \mathrm{~ms}$ (Fig. 1). The pairs were separated by a fixation cross with a duration of 5000,6250 or $7500 \mathrm{~ms}$ (4-6 functional volumes), and these interstimulus interval (ISI) durations were also fully randomized. This timing ensured that the onset of distinct events was separated by at least 6-8 functional volumes (7500-10,000 ms). Randomization of trial order and of ISI duration further reduced any potential top-down effects of anticipation of the stimuli.

All images (pictures of faces and butterflies) were presented in the central visual field in colour and subtended approximately $4{ }^{\circ}$ of visual angle. Stimuli were spatially jittered by 40 pixels in $X(5 \%)$ and 40 pixels in $Y(7 \%)$ dimensions. The pairs were displayed in random order with a PC using E-prime 1.1 (PST Inc.) and projected onto a screen located above the head of the subject and viewed through an angled mirror.

\subsection{Imaging experiments}

MR images of brain activity were acquired on all participants using a 3T head scanner (Siemens Allegra, Siemens AG, Erlangen, Germany), with repeated singleshot echo-planar imaging: echo time $(\mathrm{TE})=50 \mathrm{~ms}$, flip angle $(\mathrm{FA})=90^{\circ}$, matrix size $=64 \times 64$, field of view $($ FOV $)=224 \mathrm{~mm} \times 224 \mathrm{~mm}$, slice order descending and interleaved. Scan parameters were: repetition time (TR) $=1250 \mathrm{~ms}, 21$ slices, slice thickness $=3.5 \mathrm{~mm}$, no gap between slices, run time length $=11 \mathrm{~min}, 46 \mathrm{~s}, 250 \mathrm{~ms}$. A three-dimensional (3D) T1-weighted data set encompassing the whole brain was acquired for each subject to provide detailed anatomy $\left(1 \mathrm{~mm}^{3}\right)$ using a "modified driven equilibrium Fourier transform" (MDEFT) sequence (scan parameters: $\mathrm{TR}=7.92 \mathrm{~ms}, \mathrm{TE}=2.4 \mathrm{~ms}, \mathrm{FA}=15^{\circ}$, matrix size $=256 \times 256, \mathrm{FOV}=256 \mathrm{~mm} \times 256 \mathrm{~mm}$, 176 slices, slice thickness $=1 \mathrm{~mm}$, no gap, total scan time $=13 \mathrm{~min}$ and $43 \mathrm{~s}$ ).

\subsection{Data analysis of the imaging experiments}

The fMRI signal in the different conditions was compared using BrainVoyager QX (Version 1.4, Brain Innovation, Maastricht, The Netherlands) applying a General Linear Model analysis. Prior to analysis, the functional data sets were subjected to a series of preprocessing operations. This preprocessing consisted of linear trend removal to exclude scanner-related signal drift, temporal high-pass filtering in order to remove temporal frequencies lower than 3 cycles per run, and a correction for small interscan head movements using a rigid body algorithm rotating and translating each functional volume in 3D space (Friston, Frith, Turner, \& Frackowiak, 1995). In addition to preprocessing, the data from the event-related experiment were also corrected for the difference between the scan times of the slices. Data were not smoothed in the spatial domain but were filtered in the temporal domain (FWHM $=2.8$ cycles per second). In order to compare activated brain regions across subjects, all anatomical images and functional volumes were spatially normalized (Talairach-transformation; Talairach \& Tournoux, 1988). Computed statistical maps were overlaid on the 3D T1-weighted scans to determine Talairach coordinates for al relevant activation clusters. Subsequently, the functional data were analyzed using multiple regression models consisting of predictors, which corresponded to the particular experimental conditions of the experiment. The predictor time courses used were computed on the basis of a general linear model (GLM) of the relationship between neural activity and hemodynamic response, assuming a square wave neural response during phases of visual stimulation (Boynton, Engel, Glover \& Heeger, 1996). For our two patients and the control subjects, we computed a main effect to localize the face-preferential areas (faces versus butterflies), and tested the interaction and simple adaptation effects for each stimulus condition in these areas. Statistical thresholds were chosen with $[q$ (false discovery rate $)<0.01]$ with a minimum of 50 voxel clustering.

\section{Results}

\subsection{Behavioural data during fMRI}

All participants performed the behavioural task of indicating across-category trials at ceiling (control means: $95 \pm 0.03 \%$ ), PS (96\%) and DF (100\% correct detection but one false alarm). Patients showed comparable response latencies to each other and to controls (controls: $595 \pm 128 \mathrm{~ms}$; PS: $576 \mathrm{~ms}$; DF: $747 \mathrm{~ms}$ ) with $t=-0.100, p=0.463$ for PS and $t=1.084, p=0.17$ for DF [modified t-test (Crawford \& Garthwaite, 2002)].

\subsection{Neuroimaging results}

\subsubsection{Whole brain analysis}

3.2.1.1. Main effect of category: faces versus objects. The comparison of face and butterfly images, independent of adaptation effects, led to significant activation in several high-level visual areas for the control participants as well as for both patients (Fig. 2). Our group of normal controls (including the age-matched control) showed significant activation at $[p$ (Bonferroni-corrected $)<0.001]$ in the right and left 'FFA' (mean Talairach coordinates, right 'FFA': 39, -45 , $-19 ; 559$ voxels and left 'FFA': $-39,-43,-19 ; 777$ voxels), and [at $\mathrm{q}(\mathrm{FDR})<0.001$ ] in the right 'pSTS' (mean Talairach coordinates, 49, $-44,12 ; 77$ voxels) and in the right and left 'OFA' (mean Talairach coordinates, right 'OFA': 40, -69, $-13 ; 188$ voxels and left 'OFA': $-40,-66,-16 ; 101$ voxels).

Consistent with previous observations, there was significant activation [at $q(\mathrm{FDR})<0.001$ ] for faces in the 'FFA' and 'pSTS' of the right hemisphere for both patient PS and DF (Talairach coordinates, patient PS: 'FFA': $37,-54,-18 ; 591$ voxels and 'pSTS': 41 , $-49,14$; 37 voxels and patient DF: 'FFA': 44, $-47,-21$; 178 voxels and 'pSTS': $48,-47,-1 ; 525$ voxels) (Fig. 2 ). These activations were within the normal range for size and anatomical location as previously reported (PS: Rossion et al., 2003; Sorger et al., 2007; DF: Steeves et al., 2006). Also consistent with previous work, there was significant activation in the left 'FFA' for patient DF (Talairach coordinates: $-36,-48,-19 ; 434$ voxels) and in the left 'OFA' for patient PS [but at $p$ (uncorrected) $<0.045,-31,-81,-17 ; 30$ voxels]. In summary, the missing components of the network of face-preferential activation in both patients were areas that would have been located 


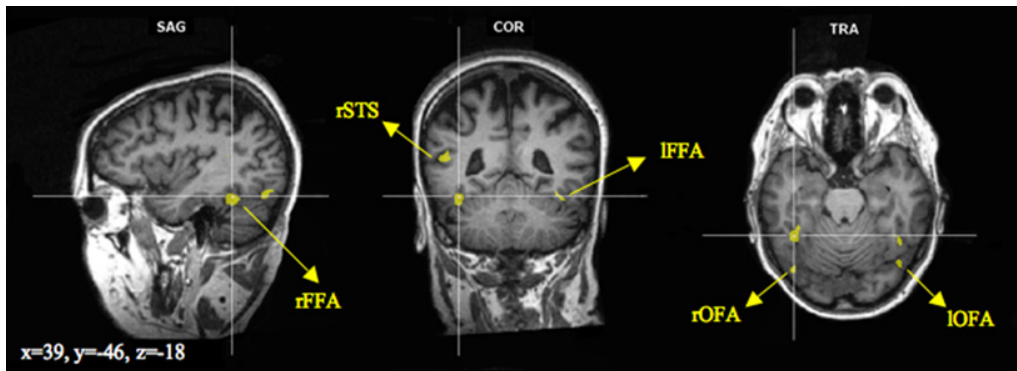

\title{
Control subject
}

\author{
Right 'FFA' (rFFA) \\ Right 'OFA (rOFA) \\ Left 'FFA' (IFFA) \\ Left 'OFA' (IOFA) \\ Right pSTS (pSTS)
}

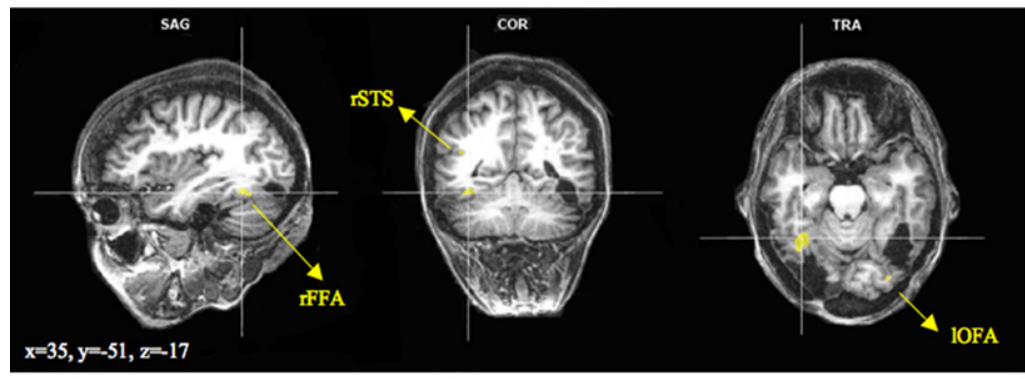

PS

\author{
Right 'FFA' (rFFA) \\ Right 'OFA (rOFA) \\ Left 'FFA' (IFFA) \\ Left 'OFA' (1OFA) \\ Right pSTS (pSTS)
}

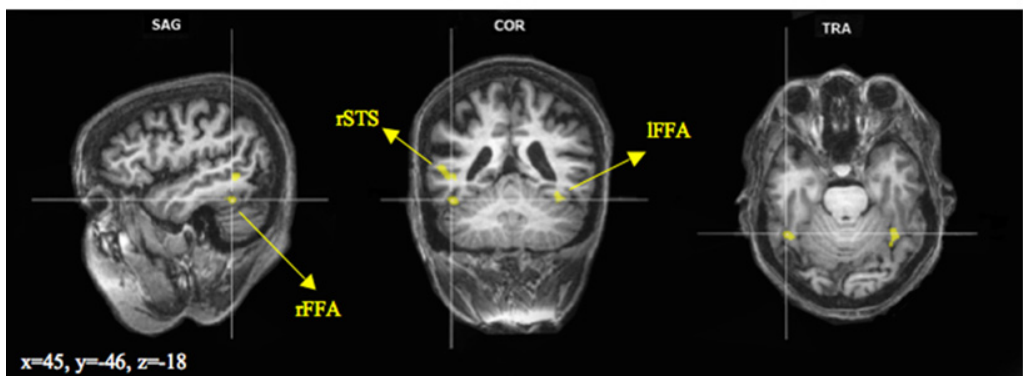

\section{DF}

\author{
Right 'FFA' (rFFA) \\ Right 'OFA (rOFA) \\ Left 'FFA' (IFFA) \\ Left 'OFA' (1OFA) \\ Right pSTS (pSTS)
}

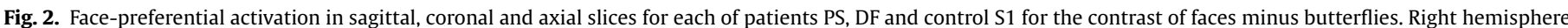

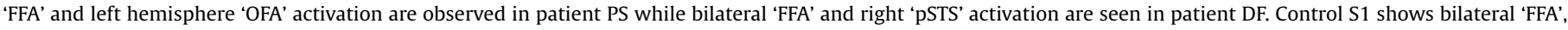
'OFA' and right hemisphere 'pSTS' activation. Talairach coordinates and cluster sizes are listed in Table 1.

in structurally damaged tissue (Fig. 2). The common lesion site in the two patients is the right hemisphere 'OFA'.

\subsubsection{ROI-based analysis}

3.2.2.1. Adaptation effects for faces. In each of the areas showing preferential activation for faces, we tested for interactions between adaptation and category, as well as separately for effects of adaptation for each of the image categories (faces and butterflies). Adaptation indices were computed using the beta weights of the general linear model $(\mathrm{GLM})$ analysis [faces index $=($ different faces versus same faces $) /($ different faces + same faces)]. Consistent with previous findings (Dricot et al., 2008; Schiltz et al., 2006), PS did not show any evidence of release from adaptation to face identity in the right 'FFA' $(t=1.499 ; p=0.1339$; Fig. 3$)$, unlike normal participants $(t=3.732 ; p<0.0002$; Fig. 3$)$. Hence, her middle fusiform gyrus responds preferentially to a picture of a face, but does not distinguish between different face identities. Strikingly, this absence of release from adaptation to face identity was also observed for the first time in the right 'FFA' of patient DF (Fig. 3) for which there was, in fact, a trend toward a pattern of activation opposite that which was expected (slightly higher signal for pairs of identical faces than different faces) $(t=-1.698, p=0.09)$. Thus, the right 'FFAs' of the two acquired prosopagnosia patients do not show release from adaptation to identity, in contrast to the healthy control participants.

Release from adaptation to identity was observed, however, in other face-preferential areas of the control participants (right 'OFA': $t=2.449, p<0.0143$ and left 'FFA': $t=2.414, p<0.0158)$ but not in the left 'OFA' $(t=0.594, p=0.5527)$ and right $\operatorname{pSTS}(t=0.644, p=0.5194)$. In contrast, none of these regions that were intact in either patient showed such effects. There was no release from adaptation to face identity for patient PS in the left 'OFA' $(t=0.242, p=0.8089)$ or right 'pSTS' $(t=0.043, p=0.9656)$ nor for patient DF in the left 'FFA' $(t=-0.967, p=0.3339)$ or the right 'pSTS' $(t=-1.442, p=0.1494)$ (Supplementary Fig. 1).

When comparing patient indices directly to those of controls, there was a significant difference in the 'FFA' for patient DF $(t=-5.07, p=0.004)$ and for patient PS $(t=-2.48, p=0.034)$.

3.2.2.2. Adaptation effects for objects. This absence of release from adaptation to identity, in particular in the right 'FFA' cannot be attributed to a lower signal overall for the patients, because this area responds robustly to faces in both patients (Fig. 3). Moreover, this area (right FFA) shows an identity adaptation effect when contrasting different and identical pictures of butterflies in not only our control participants ( $t=5.281, p<0.00001$; Fig. 3$)$, but also in patient PS ( $t=4.725, p<0.00001$; Fig. 3; see also Dricot et al., 2008). There was no such effect for patient DF $(t=-0.882, p=0.3778$; Fig. 3).

Release from adaptation to identity for butterflies was observed in other face-preferential areas of the normal participants including the right 'OFA' $(t=3.040, p<0.0024)$, left 'OFA' $(t=3.416, p<0.0006)$ and left 'FFA' $(t=5.499, p<0.00001)$ but not the right $\operatorname{pSTS}(t=0.376$, $p=0.7063)$. For patient PS, release from adaptation was found in the pSTS $(t=2.787, p<0.0053)$ but not in the left 'OFA' $(t=-0.181$, $p=0.8569$ ) and there was no release from adaptation at all for patient DF in any of the regions of interest responding preferentially to faces (left 'FFA': $t=1.331, p=0.1833$; right 'pSTS': $t=-2.075$, $p=0.0381$ ) (Supplementary Fig. 1). 
(A)

$$
\text { 'FFA': Time Courses }
$$
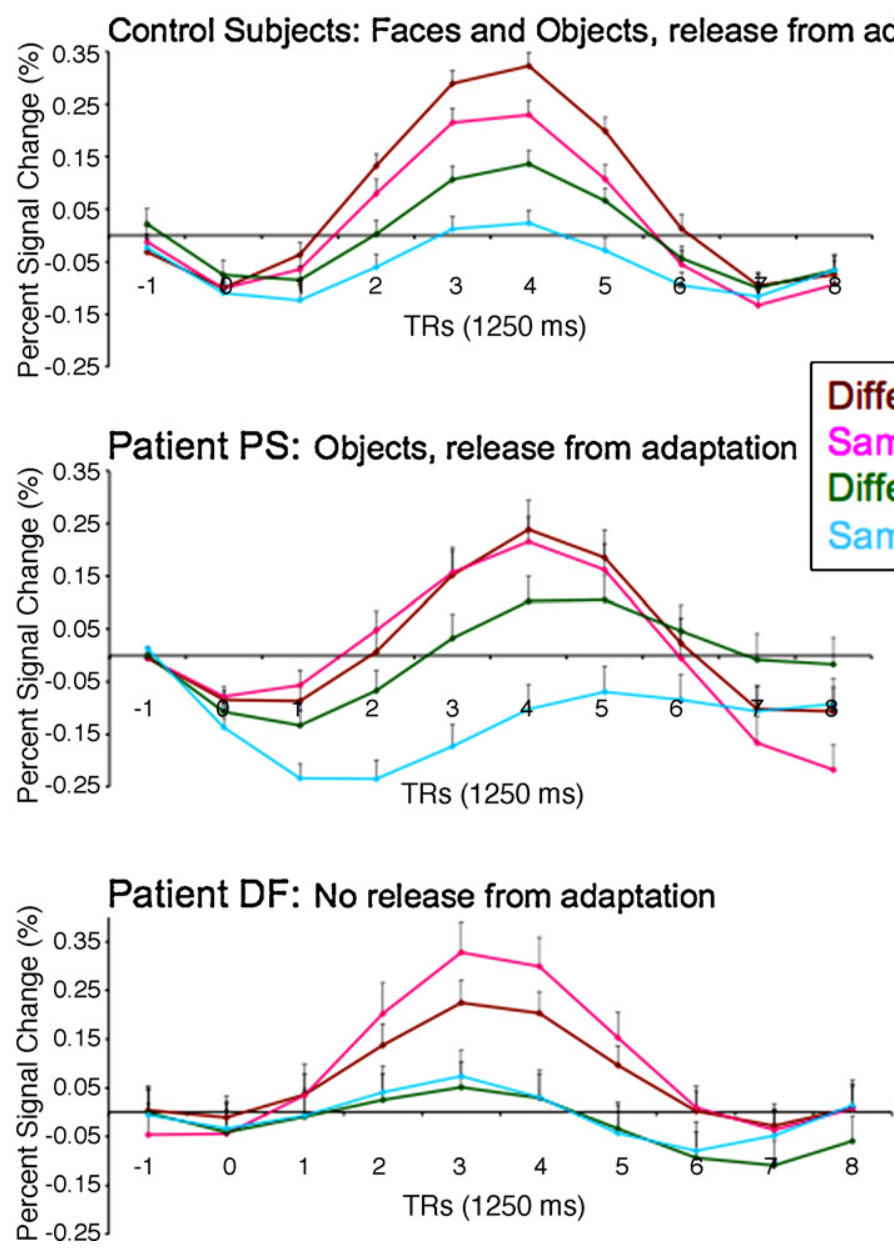

(B) 'FFA': Indices
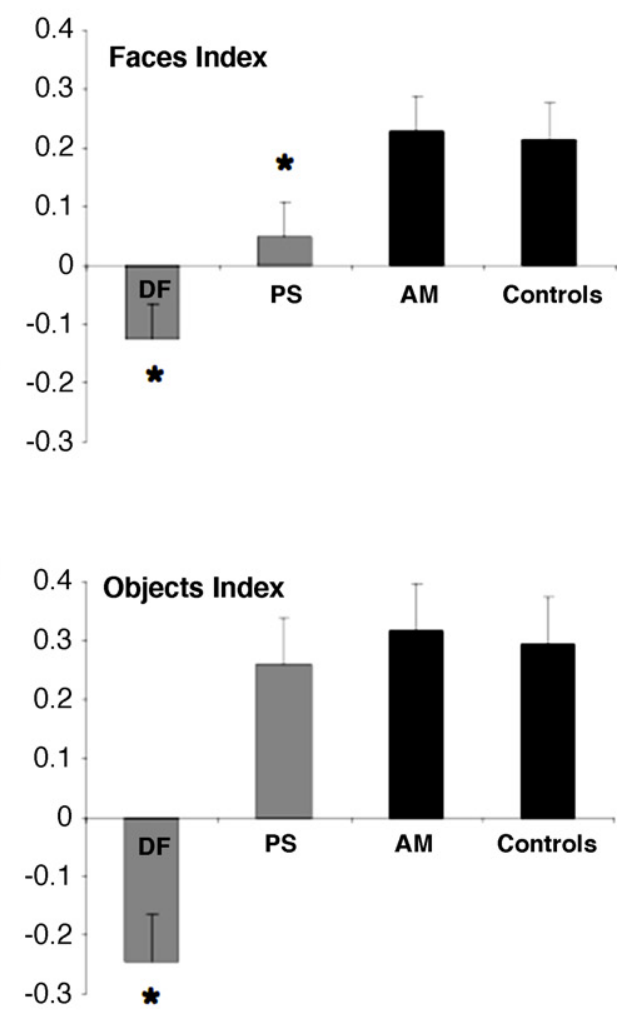

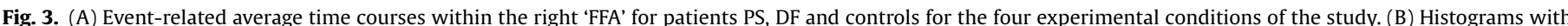

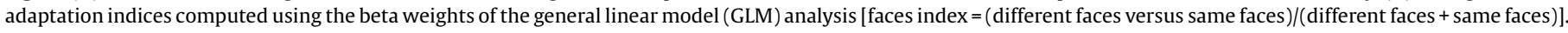
$\mathrm{AM}$ refers to the age-matched control. The * indicates a significantly different repetition index from controls.

When comparing patient indices directly to those of controls, there was a significant difference in the 'FFA' for patient DF $(t=-6.26, p=0.002)$ and but not for patient PS $(t=-0.387, p=0.36)$.

3.2.2.3. Interaction between adaptation and category. In summary, identity adaptation effects for both faces and objects were observed in normal participants in the right 'FFA' and in other facepreferential areas (Table 1). For patient PS, identity adaptation effects were only observed for objects, while for patient DF there were no adaptation effects for objects or faces. When testing the interaction between category and adaptation, normal participants showed equally large identity adaptation in the 'FFA' for faces and objects (interaction: $t=-1.091, p=0.2755$ ), while PS showed a larger effect for objects $(t=-2.293, p<0.0219)$ than for faces in the right 'FFA', and DF did not show identity adaptation for either image category in any of these areas $(t=-0.573$, $p=5665$ ).

3.2.2.4. Whole brain conjunction analysis. To strengthen our results, a whole brain analysis was performed on the control participants with the conjunction of three contrasts: [((different faces + same faces) versus (different butterflies + same butterflies)) \& (different faces - same faces) \& (different butterflies - same butterflies)]. This was done using a fixed effects analysis with our five subjects, for which we found only one significant cluster, corresponding to the
Talairach coordinates of the 'FFA' (Fig. 4): 37, -43, -22; 31 voxels, $q(\mathrm{FDR})<0.05$. The same analysis did not reveal any activation for either patient, which is consistent with their absence of adaptation effects for faces in the faces' ROI analyses. In addition, we performed a whole brain analysis searching for identity adaptation effects for pictures of faces and butterflies in patient PS and DF's brain. Consistent with our most recent findings (Dricot et al., 2008), we found a significant release from face and object identity adaptation for PS in an area adjacent to her right inferior occipital lesion, corresponding to the ventral part of the lateral occipital complex (vLOC, see Dricot et al., 2008) [Talairach coordinates: 50, $-64,-10 ; 506$ voxels at $p$ (uncorrected) $<0.045, t=3.705, p<0.0002$ for face adaptation and $t=3.206, p<0.0014$ for object adaptation without an interaction between category and adaptation $(t=0.344$, $p=0.7306$ ); Fig. 5].

This cluster is not specific to faces and responds even more to objects than to faces [contrast ([different butterflies + same butterflies] versus [different faces + same faces]), $t=2.758, p<0.0059$ ]. This indicates that patient PS recruits an area that does not respond preferentially to faces, the vLOC, to differentiate face identities. Importantly, this effect is not specific to patient PS-when the vLOC is localized independently in normal observers, this region also shows a larger response to different exemplars than same exemplars, irrespective of the category. This has been observed in several studies with normal observers (Avidan, Hasson, Hendler, 
Table 1

Talairach coordinates and cluster size in face-preferential areas for controls and patients PS and DF.

\begin{tabular}{|c|c|c|c|c|}
\hline & & Controls & PS & DF \\
\hline $\begin{array}{l}\text { Right } \\
\text { "FFA" }\end{array}$ & $\begin{array}{l}\text { Talairach coordinates } \\
\text { Size }\left[\mathrm{mm}^{2} ; q(\mathrm{FDR})<0.001\right] \\
\text { Face adaptation } \\
\text { Object adaptation }\end{array}$ & $\begin{array}{l}39,-45,-19 \\
559^{*} \\
\text { Yes } \\
\text { Yes }\end{array}$ & $\begin{array}{l}37,-54,-18 \\
591 \\
\text { No } \\
\text { Yes }\end{array}$ & $\begin{array}{l}44,-47,-21 \\
178 \\
\text { No } \\
\text { No }\end{array}$ \\
\hline $\begin{array}{l}\text { Left } \\
\text { "FFA" }\end{array}$ & $\begin{array}{l}\text { Talairach coordinates } \\
\text { Size }\left[\mathrm{mm}^{2} ; q(\mathrm{FDR})<0.001\right] \\
\text { Face adaptation } \\
\text { Object adaptation }\end{array}$ & $\begin{array}{l}-39,-43,-19 \\
111^{*} \\
\text { Yes } \\
\text { Yes }\end{array}$ & Lesioned & $\begin{array}{l}-36,-48,-19 \\
434 \\
\text { No } \\
\text { No }\end{array}$ \\
\hline $\begin{array}{l}\text { Right } \\
\text { "OFA" }\end{array}$ & $\begin{array}{l}\text { Talairach coordinates } \\
\text { Size }\left[\mathrm{mm}^{2} ; q(\mathrm{FDR})<0.001\right] \\
\text { Face adaptation } \\
\text { Object adaptation }\end{array}$ & $\begin{array}{l}40,-69,-13 \\
188 \\
\text { Yes } \\
\text { Yes }\end{array}$ & Lesioned & Lesioned \\
\hline $\begin{array}{l}\text { Left } \\
\text { "OFA" }\end{array}$ & $\begin{array}{l}\text { Talairach coordinates } \\
\text { Size }\left[\mathrm{mm}^{2} ; q(\mathrm{FDR})<0.001\right] \\
\text { Face adaptation } \\
\text { Object adaptation }\end{array}$ & $\begin{array}{l}-40,-66,-16 \\
101 \\
\text { No } \\
\text { Yes }\end{array}$ & $\begin{array}{l}-31,-81,-17 \\
30^{* *} \\
\text { No } \\
\text { No }\end{array}$ & Lesioned \\
\hline $\begin{array}{l}\text { Right } \\
\text { pSTS }\end{array}$ & $\begin{array}{l}\text { Talairach coordinates } \\
\text { Size }\left[\mathrm{mm}^{2} ; q(\mathrm{FDR})<0.001\right] \\
\text { Face adaptation } \\
\text { Object adaptation }\end{array}$ & $\begin{array}{l}49,-44,12 \\
77^{*} \\
\text { No } \\
\text { No }\end{array}$ & $\begin{array}{l}41,-49,14 \\
37 \\
\text { No } \\
\text { Yes }\end{array}$ & $\begin{array}{l}48,-47,-1 \\
525 \\
\text { No } \\
\text { No }\end{array}$ \\
\hline
\end{tabular}

${ }^{*}$ Bonferroni corrected.

Zohary, \& Malach, 2002; Grill-Spector et al., 1999; Sayres \& Grill-Spector, 2006), as well as for both faces and objects in individual normal subjects tested with the paradigm used in the present study, in which the vLOC was localized independently
(Dricot et al., 2008). Hence, the sensitivity to different individual faces in the vLOC of patient PS appears to reflect a residual rather than a compensatory mode of processing the individual face.

(A) Control subjects: contrast [(Different Faces + Same Faces) - (Different Butterflies + Same Butterflies) \& (Different Faces - Same Faces) \& (Different Butterflies - Same Butterflies)]

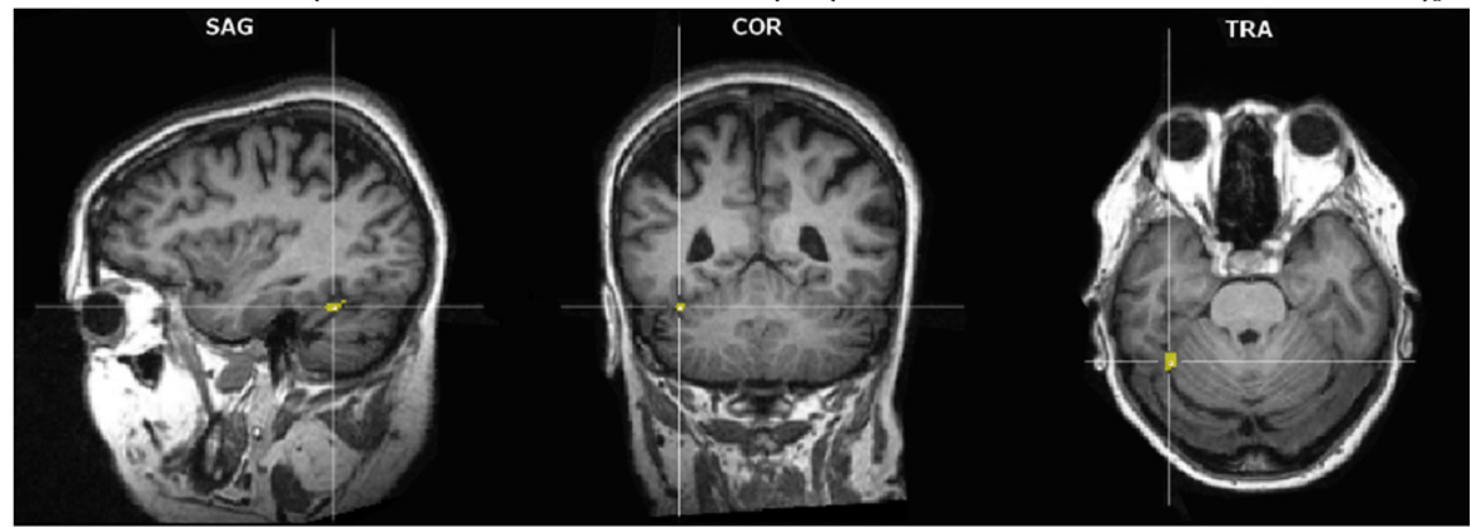

Talairach coordinates: $37,-43,-22$

(B) Control subjects: 'FFA'

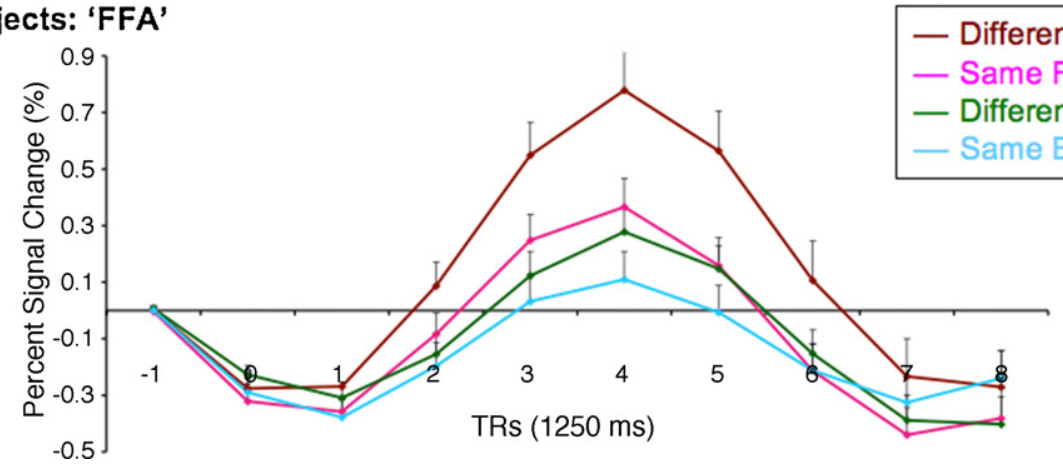

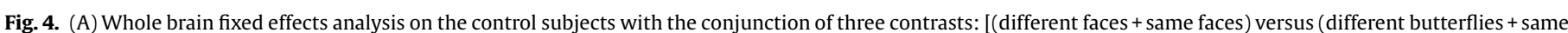

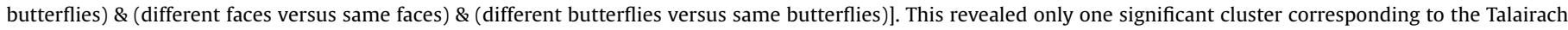

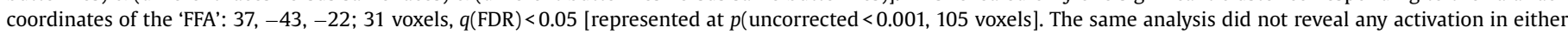
patient PS or DF. (B) Event-related average time courses for the four experimental conditions in the study. 
(A) Patient PS: contrast [(Different Faces - Same Faces) \& (Different Butterflies - Same Butterflies)]

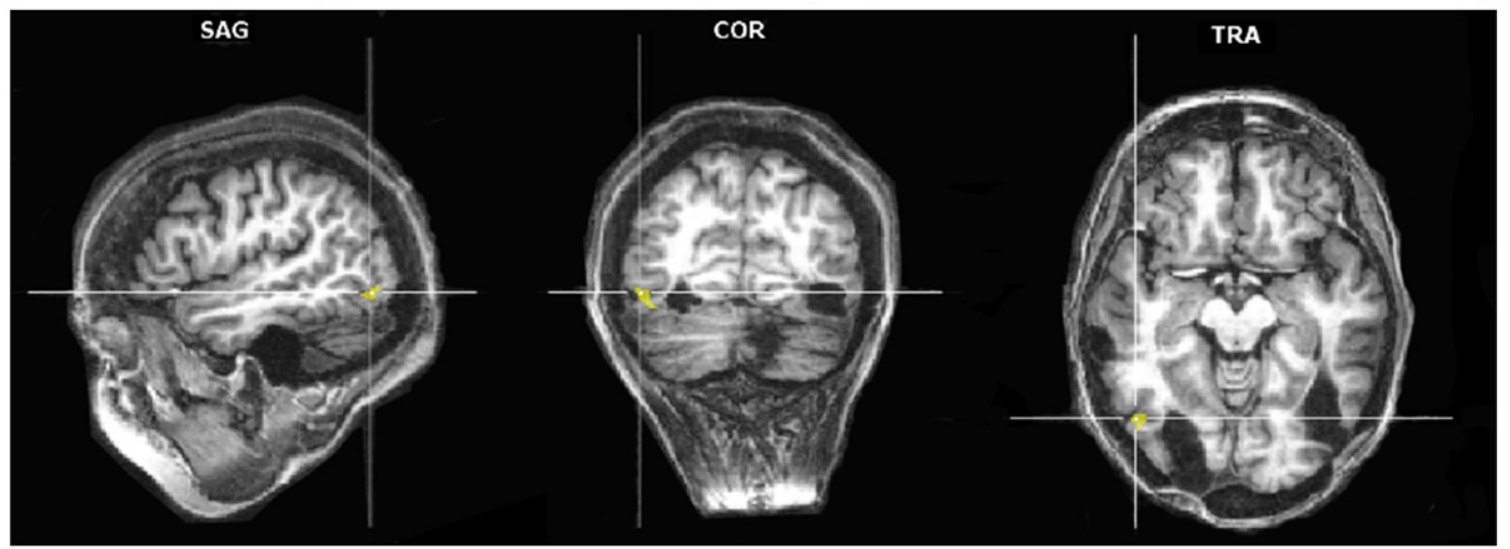

Talairach coordinates: $50,-64,-10$

(B) Patient PS: vLOC

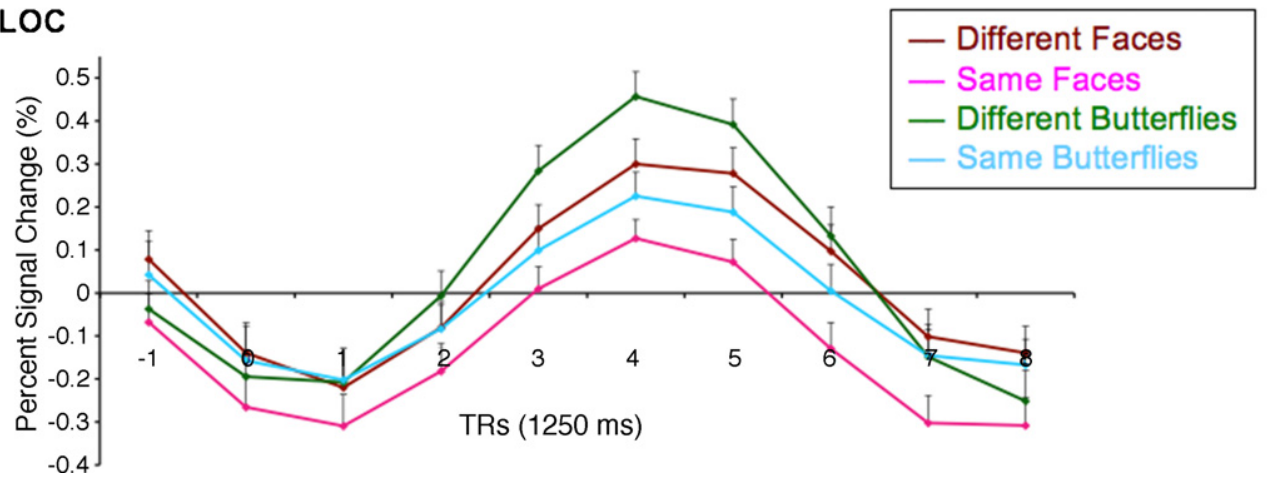

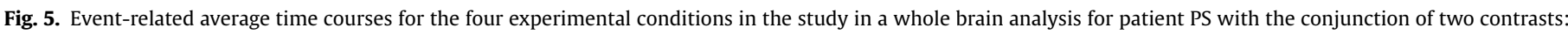

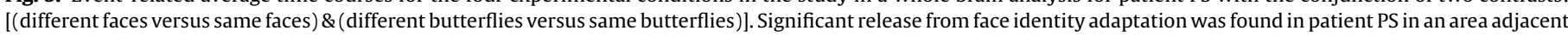

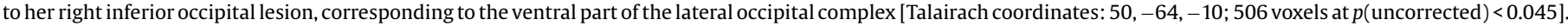
The same analysis did not reveal any activation in patient DF.

In contrast, there was no evidence for any identity adaptation effects in patient DF's brain for faces or butterflies, consistent with her general visual form agnosia.

\section{Discussion}

Within the network of occipitotemporal areas that respond preferentially to faces, our two acquired prosopagnosia patients present a common lesion site encompassing the right 'OFA'. Each of the other components of the network was intact either in one of the patients (left 'OFA' for PS; left 'FFA' for DF), or in both patients' brain (right pSTS and 'FFA'). The preferential activation for faces in the two patients was in the normal range in terms of amplitude and spatial extent, even though the large variability in patterns of activation in the healthy control participants may mask minor abnormalities at this level. That is, one can never rule out the possibility that without the lesions to other face-sensitive regions (e.g., the right 'OFA'), the level of activation in response to faces in the other components of the network might have been higher in these patients. Nevertheless, these findings strongly support the notion that, in addition to the right middle fusiform gyrus (Barton, Press, Keenan, \& O'Connor, 2002), a critical site implicated in prosopagnosia is located in the inferior occipital cortex in the right hemisphere, in the vicinity of the right 'OFA' (Bouvier \& Engel, 2006). Moreover, these data indicate that the 'OFA', whether it is located in the right or left hemisphere, does not constitute a stage of processing that necessarily has to precede and send input to the rest of the face cortical network in order for those higher areas to be activated. This observation casts doubts on a hierarchical view of face processing, advocated in several papers (Haxby et al., 2000; Ishai, 2008; see also Jiang et al., 2006; Pitcher, Walsh, Yovel, \& Duchaine, 2008). Rather, these data support the view that there must be direct connections from early visual areas that do not show preferential sensitivity to faces, to the middle fusiform gyrus and possibly the pSTS, leading to face-preferential responses in those areas (Rossion, 2008).

This hypothesis is not novel, but is reinforced by the present data and by previous observations made by two groups of independent researchers with these patients. The key observation of the present study, however, is the lack of release from adaptation to face identity in the 'FFA' of both patients DF and PS. This is consistent with previous findings observed in patient PS (Dricot et al., 2008; Schiltz et al., 2006). Behaviourally, both patients present strong impairments at individualizing faces, and they do not show the release from adaptation to face identity that is observed in the healthy control participants both in the present experiment and in numerous other studies (e.g., Gauthier et al., 2000; Grill-Spector \& Malach, 2001). Taken together, this strengthens the notion that the right 'OFA' - the two patients' common missing region within the cortical face network - is an integral component of the network for processing face identity (Gauthier et al., 2000), and is necessary for this function. Its role within this network may not be to precede the preferential activation for faces at the level of the FFA but rather its role in face identity processing, in particular in the right hemisphere, may be to contribute to the refinement of the face representation, following the initial categorization of a 
face in the "higher-order" right 'FFA' (Rossion, 2008). This reverse hierarchical view (Hochstein and Ahissar, 2002) of face perception is consistent with the presence of massive cortical bi-directional connections (Felleman \& Van Essen, 1991) and the hypothesis of reentrant phasic signaling between areas of visual cortex (Edelman, 1978,1993 ). In a similar vein, a number of authors have suggested that higher level perceptual computations and representations that require high resolution details, fine geometry and spatial precision may involve lower visual areas through feedback connections (Bullier et al., 2001; Galuske et al., 2002; Mumford, 1992; Lee et al., 1998). For the recognition of face identity, refinement in the initial coarse face representation would require the high resolution details both at the level of the face features and of its configuration (Sergent, 1986).

Despite presenting a common lesion in the right inferior occipital cortex that is most likely critical in causing their face processing impairment (Bouvier \& Engel, 2006), patients PS and DF do not present the same neuropsychological profile. While patient DF has a visual form agnosia, and is unable to recognize common objects (Milner et al., 1991), patient PS does not present any difficulty in recognizing objects, whether they have to be identified or discriminated at the basic-level or at more fine-grained categorization levels (Rossion et al., 2003; Schiltz et al., 2006). Consistent with these behavioural differences, patient DF has bilateral damage to the lateral occipital area (LO, James et al., 2003), while this region is both structurally and functionally intact for patient PS (bilateral dorsal LO and right ventral LO, Sorger et al., 2007). Moreover, patient PS' area LO shows a larger response to normal shapes compared to scrambled shapes (Sorger et al., 2007), and it also shows release from adaptation to the repetition of the same object shape (Dricot et al., 2008; the present study).

In addition, we note that while patient PS showed a significant release from adaptation in the right 'FFA' to object shapes, patient DF did not. This is an interesting observation because patient DF is able to discriminate some non-face stimuli, particularly natural objects such as fruits and vegetables based on surface properties such as colour (Humphrey et al., 1994), yet her right 'FFA' did not show release from adaptation in this condition. This suggests that the positive adaptation effect observed for patient PS in the 'FFA' for objects (Dricot et al., 2008) may not be attributable to a simple release from adaptation driven by colour alone.

Further to these differences in object recognition, the two patients are not equally strongly impaired with respect to face processing. Patient DF is severely impaired in individual face discrimination, scoring generally at chance levels (Steeves et al., 2006). Patient PS, however, is impaired relative to controls but nonetheless performs well above chance levels in individual face discrimination tasks (Rossion et al., 2003; Schiltz et al., 2006). Previous studies have shown that patient PS relies on suboptimal cues to discriminate and recognize individual faces (e.g., the mouth and lower external contour; Caldara et al., 2005), and appears to analyze each facial feature consecutively, in detail, rather than resorting to an efficient holistic processing of the individual face, as do normal observers (Orban de Xivry, Ramon, Lefèvre, \& Rossion, 2008). The imaging data for patient PS collected previously (Dricot et al., 2008) and that in the present study suggest that this sub-efficient, analytical mode of processing the individual face does not rely on areas responding preferentially to faces, but may involve more general processes in the ventral part of the lateral occipital complex.

Another original aspect of the present experiment lies in the fact that while patient DF's face-preferential regions in the middle fusiform gyrus ('FFA') were reported previously in a block design face localizer experiment (Steeves et al., 2006), this is the first time that this face selective-activation is reported in an ER design, limiting the putative role of top-down influences on the activation of the 'FFA'. This is an important observation, since it is known that the 'FFA' can be modulated and activated through top-down processes, for instance through visual imagery of faces (O'Craven \& Kanwisher, 2000) or recognizing the voices of familiar people (von Kriegstein et al., 2005). In the kind of paradigm used here, the participant does not know in advance which stimulus category will be presented (pair of faces or objects) and thus anticipatory top-down processes cannot account for the differential activity observed in these areas. A further novel aspect of the present study is that we used a different category for the contrast compared to the previous study with patient DF (Steeves et al., 2006). Here we define these areas by contrasting faces with objects while the previous study contrasted faces with scenes.

In summary, the present study compared functional brain activation in two unique brain-damaged patients who both suffer from acquired prosopagnosia. The findings strengthen the critical role of the right inferior occipital cortex, in the vicinity of the right 'occipital face area', in acquired prosopagnosia (Bouvier \& Engel, 2006; Sorger et al., 2007). Damage to this region does not prevent overall face sensitivity within the right middle fusiform gyrus ('FFA'), thus arguing against a strict hierarchical view of face processing in the human brain. However, right 'OFA' damage does appear to prevent the differential sensitivity of the 'FFA' to different face identity, suggesting a reentrant role of the right 'OFA' in extracting fine-grained individual representations of faces in the normal brain.

\section{Acknowledgements}

This study was supported by grants from the Belgian National Fund for Scientific Research (FNRS) and a grant ARC 07/12-007 to BR (Mandat d'Impulsion Scientifique), the Natural Sciences and Engineering Research Council of Canada (NSERC) to JS and the Medical Research Council (MRC) \# G0401090 to AM. We thank two anonymous reviewers for their helpful comments on a previous version of the paper.

\section{Appendix A. Supplementary data}

Supplementary data associated with this article can be found, in the online version, at doi:10.1016/j.neuropsychologia.2009.05.005.

\section{References}

Allison, T., McCarthy, G., Nobre, A., Puce, A., \& Belger, A. (1994). Human extrastriate visual cortex and the perception of faces, words, numbers, and colors. Cerebral Cortex, 4(5), 544-554.

Avidan, G., Hasson, U., Hendler, T., Zohary, E., \& Malach, R. (2002). Analysis of the neuronal selectivity underlying low fMRI signals. Current Biology, 12, 964-972.

Avidan, G., Hasson, U., Malach, R., \& Berhmann, M. (2005). Detailed exploration of face-related processing in congenital prosopagnosia. 2. Functional neuroimaging findings. Journal of Cognitive Neuroscience, 17(7), 1150-1167.

Barton, J. J., Press, D. Z., Keenan, J. P., \& O'Connor, M. (2002). Lesions of the fusiform face area impair perception of facial configuration in prosopagnosia. Neurology, $58,71-78$.

Bodamer, J. (1947). Die-Prosop-agnosie. Arch. Psychiatr. Nervenkrankh., 179, 6-54. English translation by Ellis, H.D. and Florence, M. (1990). Cognitive Neuropsychology, 7, 81-105.

Bouvier, S. E., \& Engel, S. A. (2006). Behavioral deficits and cortical damage loci in cerebral achromatopsia. Cerebral Cortex, 16(2), 183-191.

Boynton, G. M., Engel, S. A., Glover, G. H., \& Heeger, D. J. (1996). Linear systems analysis of functional magnetic resonance imaging in human V1. Journal of Neuroscience, 16, 4207-4221.

Brodtmann, A., Puce, A., Syngeniotis, A., Darby, D., \& Donnan, G. (2003). The functional magnetic resonance imaging hemodynamic response to faces remains stable until the ninth decade. Neuroimage, 20,520-528.

Bullier, J., Hupe, J. M., James, A. C., \& Girard, P. (2001). The role of feedback connections in shaping the responses of visual cortical neurons. Progress in Brain Research, $134,193-204$.

Caldara, R., Schyns, P., Mayer, E., Smith, M. L., Gosselin, F., \& Rossion, B. (2005). Does prosopagnosia take the eyes out of face representations? Evidence for a defect in representing diagnostic facial information following brain damage. Journal of Cognitive Neuroscience, 17(10), 1652-1666.

Crawford, J. R., \& Garthwaite, P. H. (2002). Investigation of the single case in neuropsychology: Confidence limits on the abnormality of test scores and test score differences. Neuropsychologia, 30, 1196-1208. 
Damasio, A. R., Damasio, H., \& Van Hoesen, G. W. (1982). Prosopagnosia: Anatomic basis and behavioral mechanisms. Neurology, 32, 331-341.

Dricot, L., Sorger, B., Schiltz, C., Goebel, R., \& Rossion, B. (2008). The roles of "face" and "non-face" areas during individual face perception: Evidence by fMRI adaptation in a brain-damaged prosopagnosic patient. Neuroimage, 40(1), 318-332.

Edelman, G. M. (1978). Group selection and phasic reentrant signaling: a theory of higher brain function. In F. O. Schmitt (Ed.), The mindful brain. Cambridge: MIT Press.

Edelman, G. M. (1993). Neural Darwinism: Selection and Reentrant Signaling in Higher Brain Function. Neuron, 10, 115-125.

Felleman, D. J., \& Van Essen, D. C. (1991). Distributed hierarchical processing in the primate cerebral cortex. Cerebral Cortex, 1, 1-47.

Friston, K. J., Frith, C. D., Turner, R., \& Frackowiak, R. S. (1995). Characterizing evoked hemodynamics with fMRI. Neuroimage, 2, 157-165.

Galuske, R. A., Schmidt, K. E., Goebel, R., Lomber, S. G., \& Payne, B. R. (2002). The role of feedback in shaping neural representations in cat visual cortex. Proceedings of the National Academy of Sciences of the United States of America, 99, 17083-17088.

Gauthier, I., Tarr, M. J., Moylan, J., Skudlarski, P., Gore, J. C., \& Anderson, A. W. (2000) The fusiform "face area" is part of a network that processes faces at the individual level. Journal of Cognitive Neuroscience, 12, 495-504.

Grill-Spector, K., \& Malach, R. (2001). fMR-adaptation: A tool for studying the functional properties of human cortical neurons. Acta Psychologica, 107, 293-321.

Grill-Spector, K., Kushnir, T., Edelman, S., Avidan, G., Itzchak, Y., \& Malach, R. (1999). Differential processing of objects under various viewing conditions in the human lateral occipital complex. Neuron, 24, 187-203.

Grill-Spector, K., Sayres, R., \& Ress, D. (2006). High-resolution imaging reveals highly selective nonface clusters in the fusiform face area. Nature Neuroscience, 9 , 1177-1185.

Haxby, J. V., Hoffman, E. A., \& Gobbini, I. A. (2000). The distributed neural system for face perception. Trends in Cognitive Sciences, 4, 223-233.

Hochstein, S., \& Ahissar, M. (2002). View from the top: hierarchies and reverse hierarchies in the visual system. Neuron, 36(5), 791-804. Review

Humphrey, G. K., Goodale, M. A., Jakobson, L. S., \& Servos, P. (1994). The role of surface information in object recognition: Studies of a visual form agnosic and normal subjects. Perception, 23, 1457-1481.

Ishai, A. (2008). Let's face it: It's a cortical network. Neuroimage, 40(2), 415-419.

James, T. W., Culham, J., Humphrey, G. K., Milner, A. D., \& Goodale, M. A. (2003). Ventral occipital lesions impair object recognition but not objectdirected grasping: An fMRI study. Brain, 126, 2643-2675.

Jiang, X., Rosen, E., Zeffiro, T., Vanmeter, J., Blanz, V., \& Riesenhuber, M. (2006). Evaluation of a shape-based model of human face discrimination using FMRI and behavioral techniques. Neuron, 50, 159-172.

Kanwisher, N., McDermott, J., \& Chun, M. M. (1997). The fusiform face area: A module in human extrastriate cortex specialized for face perception. Journal of Neuroscience, $17,4302-4311$.

Lee, T. S., Mumford, D., Romero, R., \& Lamme, V. A. (1998). The role of the primary visual cortex in higher level vision. Vision Research, 38, 2429-2454.

Marotta, J. J., Genovese, C. R., \& Behrmann, M. (2001). A functional MRI study of face recognition in patients with prosopagnosia. Neuroreport, 13, 1581-1587.

Milner, A. D., Perrett, D. I., Johnston, R. S., Benson, P. J., Jordan, T. R., Heeley, D. W., et al. (1991). Perception and action in "visual form agnosia. Brain, 114, 405-428.

Mumford, D. (1992). On the computational architecture of the neocortex II. The role of cortico-cortical loops. Biological cybernetics, 66, 241-251.

O'Craven, K. M., \& Kanwisher, N. (2000). Mental imagery of faces and places activates corresponding stiimulus-specific brain regions. Journal of Cognitive Neuroscience, 12(6), 1013-1023.
Oldfield, R. C. (1971). The assessment and analysis of handedness: The Edinburgh inventory. Neuropsychologia, 9, 97-113.

Orban de Xivry, J.-J., Ramon, M., Lefèvre, P., \& Rossion, B. (2008). Reduced fixation on the upper area of personally familiar faces following acquired prosopagnosia. Journal of Neuropsychology, 2, 245-268.

Pitcher, D., Walsh, V., Yovel, G., \& Duchaine, B. (2008). TMS evidence for the involvement of the right occipital face area in early face processing. Current Biology, 17, 1568-1573.

Puce, A., Allison, T., Gore, J. C., \& McCarthy, G. (1995). Face-sensitive regions in human extrastriate cortex studied by functional MRI. Journal of Neurophysiology, 74, 1192-1199.

Quaglino, A., \& Borelli, G. (1867). Emiplegia sinistra con amaurosi - guarigione perdita totale della percezione dei colori e della memoria della configurazione degli oggetti. Giornale d'Oftalmologia Italiano, 10, 106-117.

Rossion, B. (2008). Constraining the cortical face network by neuroimaging studies of acquired prosopagnosia. NeuroImage, 40, 423-426.

Rossion, B., Caldara, R., Seghier, M., Schuller, A.-M., Lazeyras, F., \& Mayer, E. (2003). A network of occipito-temporal face-sensitive areas besides the right middle fusiform gyrus is necessary for normal face processing. Brain, 126 2381-2395.

Sayres, R., \& Grill-Spector, K. (2006). Object-selective cortex exhibits performanceindependent repetition suppression. Journal of Neurophysiology, 95, 995-1007.

Schiltz, C., Sorger, B., Caldara, R., Ahmed, F., Mayer, E., Goebel, R., et al. (2006) Impaired face discrimination in acquired prosopagnosia is associated with abnormal response to individual faces in the right middle fusiform gyrus. Cerebral Cortex, 16(4), 574-586.

Sergent, J. (1986). Microgenesis of face perception. In H. D. Ellis, M. A. Jeeves, F. New combe, \& A. M. Young (Eds.), Aspects of face processing (pp. 17-33). Dordrecht: Martinus Nijhoff.

Sergent, J., \& Signoret, J. L. (1992). Varieties of functional deficits in prosopagnosia. Cerebral Cortex, 2, 375-388.

Sergent, J., Ohta, S., \& MacDonald, B. (1992). Functional neuroanatomy of face and object processing. A positron emission tomography study. Brain, 115, 15-36.

Servos, P., Goodale, M. A., \& Humphrey, G. K. (1993). The drawing of objects by a visua form agnosic: Contribution of surface properties and memorial representations. Neuropsychologia, 31, 251-259.

Sorger, B., Goebel, R., Schiltz, C., \& Rossion, B. (2007). Understanding the functional neuroanatomy of acquired prosopagnosia. Neuroimage, 35(2), 836-852.

Steeves, J. K. E., Humphrey, G. K., Culham, J. C., Menon, R. S., Milner, A. D., \& Goodale, M. A. (2004). Behavioral and neuroimaging evidence for a contribution of color and texture information to scene classification in a patient with visual form agnosia. Journal of Cognitive Neuroscience, 16(6), 955-965.

Steeves, J. K. E., Culham, J. C., DuChaine, B. C., Cavina Pratesi, C., Valyear, K., Schindler I., et al. (2006). The fusiform face area is not sufficient for face recognition: Evidence from a patient with dense prosopagnosia and no occipital face area. Neuropsychologia, 44(4), 596-609.

Talairach, G., \& Tournoux, P. (1988). Co-planar stereotaxic atlas of the human brain. New York: Thieme.

von Kriegstein, K., Kleinschmidt, A., Sterzer, P., \& Giraud, A. L. (2005). Interaction of face and voice areas during speaker recognition.Journal of Cognitive Neuroscience 17(3), 367-376.

Winston, J. S., Henson, R. N. A., Fine-Goulden, M. R., \& Dolan, R. J. (2004). fMRIadaptation reveals dissociable neural representations of identity and expression in face perception. Journal of Neurophysiology, 92, 1830-1839. 